\title{
The invention of a tube audio amplifier
}

\author{
Victor M. Pestrikov* \\ Saint-Petersburg State University of Film and Television \\ 13, Pravda Str., Saint-Petersburg, 191119, Russian Federation
}

\begin{abstract}
Audion as an amplifier of radio signals, whether telegraphic or telephone, was far ahead of any other amplifier that has ever been developed. For several years, from 1907 to 1911, audion was used only as a sensitive detector for receiving radio signals. The general principles of his work were not understood. De Forest conducted some experimental work on the use of an audion amplifier as a telephone repeater, however, his early development was unsuccessful. This was due to the fact that he did not attach much importance to the amount of displacement on the grid of the audion. He tried to amplify a low-frequency signal (AF) with an offset value on a grid designed to amplify a high-frequency signal (RF). In 1912, the first sound amplifier was built by Fritz Lowenstein, a former employee of the Forest company.
\end{abstract}

\section{Introduction}

The Audion was used only as a radio signal detector for nearly five years after its invention, as the amplification mechanism and General principles of its operation were not understood. De Forest did some experimental work on the development of low-frequency amplifiers for telephone repeaters, but his early attempts in this direction were unsuccessful. This is probably due to the fact that he used detection modes instead of the mode amplification and properly set the bias on the tube grid.

Originally, Lee de Forest radios were assembled on a single Audion-type tubular triode. In these radio receivers the Audion operated in grid detection mode. As a result of detection, low-frequency voltage was created on its grid, which was then amplified by the lamp itself. Thus, the Audion simultaneously served both as a detector and an amplifier. Because of this, among the known detectors of the time, the Audion was considered the most stable and sensitive receiver of radio waves.

During 1907-1910 Lee de Forest himself, as well as the developers of the receivers on the Audion, were unaware of its ability to amplify electrical signals.

The design of the Audion was known to radio engineers in many countries, some of them copied it for use in their radio devices, and others were engaged in its improvement, trying to create on its basis their original three-electrode tube.

\section{Radio frequency amplifier Bronk}

In 1911, a three-electrode tube based on an electric lamp for a Christmas tree garland, with a low filament voltage, was developed by the manager of the patent department of A.E.G.-

*Corresponding author: pvm205@yandex.ru 
Telefunken Otto Romanus von Bronk (02.29.1872-05.08.1951). He used two rods of thick copper wire as electrodes. The rods were fused inside a glass container over a filament. One of the rods played the role of a grid and was located between the second rod-anode and the filament. The lamp had a standard threaded base E14. Pressed tungsten was used to make the thread. Outside the glass bottle, lead wires were welded to the ends of the rods. Von Bronk designed this lamp for a high-frequency amplifier, which turned on in front of the detector stage. The development of Bronk was based on the patent DE249142, which was received by his colleagues in the company R. von Lieben, E. Reisz and S. Strauss. In this patent, possible options for applying bias to the grid of a three-electrode tube of their design were given.

On September 3, 1911, Otto von Bronk patented a crystal radio detector circuit with a radio frequency amplification cascade on a vacuum triode [1]. In the diagram (Fig. 1), the crystal detector is indicated by the letter $l$.
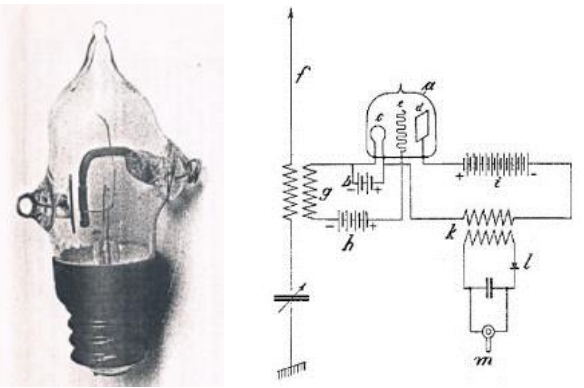

Fig. 1. Bronk's vacuum triode and a detector receiver circuit with a radio frequency amplifier on it. Patent of Bronk DRP271059 (1911).

This was essentially the first patent in which a vacuum three-electrode tube was used in a cascade to amplify electrical signals, in particular radio frequency signals. It should be noted that in this von Bronk's patent there is no mention of the choice of the bias value on the grid of the vacuum triode, on which its operation mode depends (only detection or only amplification of electrical signals). In the patent scheme, a cascade on a three-electrode lamp is presented as a radio frequency amplifier, while the grid is connected to the plus of a galvanic battery. With such potential on the grid, the tube mode is closer to detection.

It should be noted that the circuit of the radio frequency amplifier on the von Bronk vacuum triode resembles the circuit of the audion receiver given in the patent of the famous American radio engineer John Stone Stone (09.24.1863-20.05.1943) and an employee of his company Sewall Cabot, Fig. 2 [2].
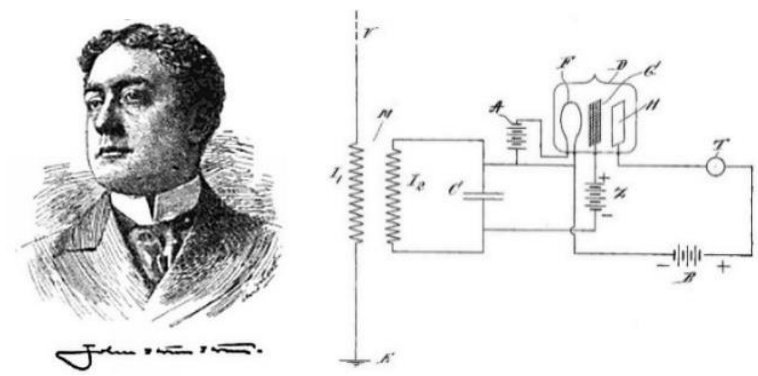

Fig. 2. John S. Stone (1910) and circuit diagram of an audion receiver with bias to the grid from a galvanic cell. J. Stone's Patent US884110A (1907).

The John S. Stone's patent provides the functional power of an audion from three separate galvanic batteries probably for the first time. Further, in the English-language technical literature of those years, the name was assigned to these batteries: " $\mathrm{A}$ " battery power supply for the filament, "B" battery - anode battery, "C" battery - the bias battery of the grid potential of the vacuum triode.

J. Stone and S. Cabot did not develop three-electrode lamps in the future and confined themselves to the obtained patent. 


\section{Lowenstein audio frequency amplifier}

Investigations of the possibilities of using audion as an amplifier for electrical signals were carried out by engineers in various laboratories around the world. An important step in this direction was made by the Austrian engineer Fritz Lowenstein (Loewenstin, German: Fritz Löwenstein), 09.07.1874-27.05.1922), who worked in the USA. He found that applying a small amount of negative bias to the audion grid improves its performance.

Fritz Lowenstein comes from the city Ostrov Schlackenwerth (Bohemia region, Austria-Hungary), he immigrated to the United States in 1899. First, he worked as an assistant to Nikola Tesla in his New York laboratory (Colorado Springs), where he dealt with the problems of wireless energy transmission from a distance. Here he gained some experience with the Hewett mercury lamp, which he later used to design a telephone amplifier. He was also involved in the development of powerful AC to DC converters. In the fall of 1899, Lowenstein left Tesla and went to work for the company of Lee de Forest, where he become familiarized with the design of the audion.

In 1910, De Forest Radio Telephone \& Telegraph Co. (New York) went bankrupt. By this time, Lee de Forest managed to create a small group of talented engineers who were well versed in the device of the audion and in the schemes for its inclusion. The suspension of salary payment led to the departure of this group of specialists from the company, who took the audion technology with them and the assumption that audion can be used not only for detection, but also for other purposes.

Among the experts departed from Lee de Forest was an engineer Fritz Lowenstein as well. In 1910, he organized his own company in Brooklyn (New York City), which was named as Lowenstein Radio Company (Nassau Street, Brooklyn, N.Y.). The company provided consulting services in the field of radio engineering.

Lowenstein Company was joined by a Swiss-born capable engineer, Frederick Augustus Kolster (13.01.1883-23.07.1950), who also worked from 1909 to 1911 for de Forest. It should be noted that Fritz Lowenstein was a famous radio engineer, so in 1911-1912 he was the first Vice-President of SWTE (Society of Wireless Telegraph Engineers), and then in IRE.

In May 1911, Fritz Lowenstein was invited as a consultant to the research laboratory of John Hays Hammond, Jr. (1888-1965) in Gloucester (Massachusetts), in which they studied the possibilities of radio control of torpedoes and ships for the US Navy, Fig. 3. He became known as the "Father of Radio Control." Hammond Jr.'s pioneering electronic remote controls have been the basis for all modern radio control devices, including advanced missile guidance systems, unmanned aerial vehicles (UAV) and unmanned combat aerial vehicle (UCAV).
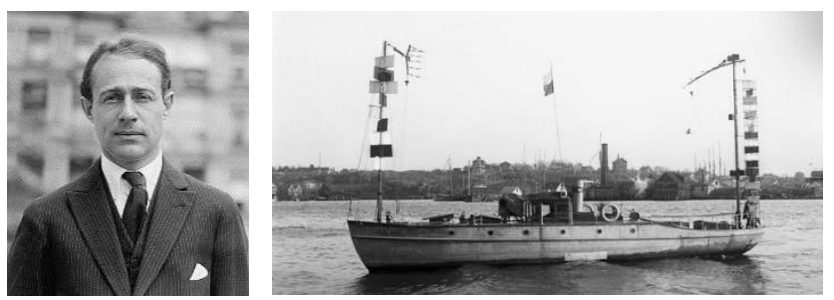

Fig. 3. John Hammond Jr. (1922) and his wireless torpedo boat "Natalie" (November 23, 1914).

Before the arrival of Fritz Lowenstein, J. Hammond did not have much success in this area. For remote control, a system consisting of a spark transmitter and a receiver with a Marconi coherer was used. Funding for the research of J. Hammond was proved by his father, who was a mining engineer and worked with Cecil Rhodes in South Africa, where he made a very large fortune on diamonds. J. Hammond was not an outstanding scientist, but he had a remarkable ability to gather talented creative people around him, to whom he indicated the direction of scientific research and provided for this organizational and 
necessary financial support. Thanks to this, in a short period of time, the Hammond laboratory became one of two science and technology centers in the United States where important work was done to improve the audion system.

The Lowenstein research program included the development of a radio control system, as well as an analysis of existing designs of detectors and amplifiers of electrical signals. As a radio wave transmitter, he planned to use undamped oscillator generators: the Alexanderson machine generator and the Paulsen arc generator.

From experiments with a mercury lamp, he knew that this lamp, like the arcs of Duddel and Paulsen, had negative resistance. Based on this, Lowenstein turned his attention to the audion of de Forest, which, for his reasons, resembled a mercury lamp. This was the starting point at the beginning of the experiments with the audion, to check whether it also has negative resistance. If so, then the way was opened for the use of an audion to amplify electrical signals.

It should be noted that Lowenstein, even before working with Hammond, conducted research on the use of audion as an amplifier. About this Lowenstein writes in a letter to Hammond of September 19, 1911, in which he notes his "efforts to conduct telephone tests last winter" [3], that is, in the winter of 1909-1910. From another document, a written application submitted by Fritz to the patent examiner during the judicial review of his patent application, it became known about his use of negative bias on the grid or battery "C", patent US1231764 from 1912-1917.

Having analyzed the results of his previous studies on this problem, Lowenstein continued the development of a three-element ion controller for rectifier control relays in New York in 1911, as well as for amplifying electrical signals. In order to hide from the competition the design of the audion of de Forest, which was used in his designs, he gave it another name - the ion controller. This name was also used in the technical documentation of the developed devices in the Hammond laboratory.

To finance these studies, he signed a contract with Hammond on the condition that he would receive $50 \%$ of the profit from the implementation of the results of the work if they were successful. Lowenstein had already attempted to use audion as an electric signal amplifier when he worked for De Forest Radio Telephone \& Telegraph Co. and achieved some success. The initial difficulties in obtaining a sufficiently high vacuum (of the order of 10-6 mm Hg) were overcome by him, and on November 13, 1911, he announced success. This made it possible to make an amplifier on an audion. The device was tested at the beginning on the telephone line and showed good results. The transmitted human voice was very loud and clear.

The resumption of research by Lowenstein in 1911 was probably prompted by information from Germany about the work of von Lieben. It is known that Fritz followed literature in German, and Hammond's trip to Germany in the summer of 1911 allowed him to become acquainted with European studies. Therefore, until the end of 1911, Lowenstein had not yet studied the circuit of the grid of the audion (Fig. 4a). In September 1911, representatives of von Lieben appeared at the US Patent Office. Their main goal was to resolve the issue of obtaining an American patent for a three-electrode lamp LR (LiebenReisz) in a circuit of a telephone amplifier with an offset to the grid, Fig. 4b.

The current situation forced Lowenstein to reconsider the role of the capacitor in the triode grid circuit. Therefore, it cannot be argued that Lowenstein was the first to apply negative bias to the grid of a vacuum triode. Despite this, the main thing in the Lowenstein sound amplifier was that he excluded the capacitor C " from the Forest circuit (Fig. 4a), through which an electric signal passed to the grid. Depending on which half-wave of the incoming radio signal arrived (negative or positive); a new offset sign appeared on the grid each time. This was one of the reasons for the unstable operation of the audion. To eliminate it, Lowenstein applied a constant negative bias from the $\mathrm{C}$ battery to the grid (in Fig. 4c). 


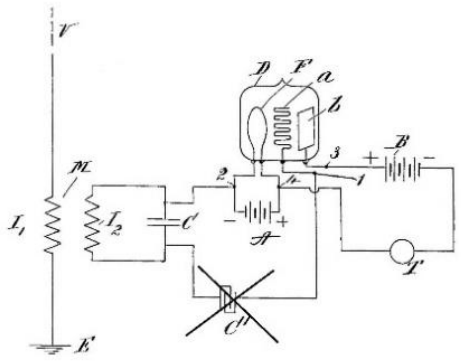

a

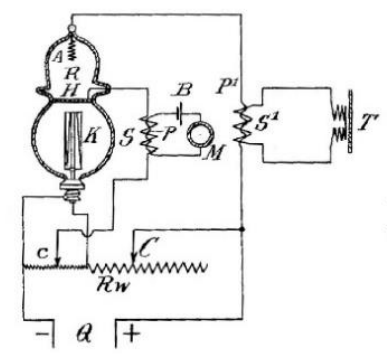

b

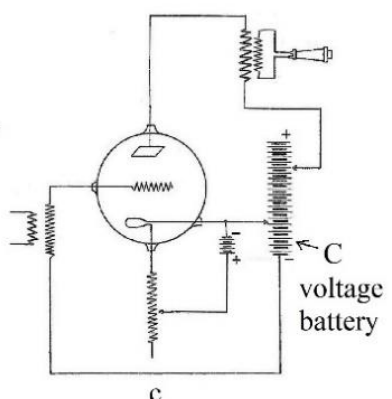

Fig. 4. Radio circuit without capacitor $C^{\prime}$ (a), telephone amplifier (Figure b from US1038910) and audio amplifier circuit Lowenstein with bias battery $\mathrm{C}$ (c).

In other words, Lowenstein understood that in order for the audion to work in amplification mode, it is necessary to select the appropriate mode of operation. The main thing in this case is the supply to the grid of the audion of a certain amount of constant negative voltage, called negative bias. This mode allows the audion to work on a straight section of its characteristic (the relationship between the voltage on the grid and the anode current), in the absence of current in the grid circuit, Fig. 4.

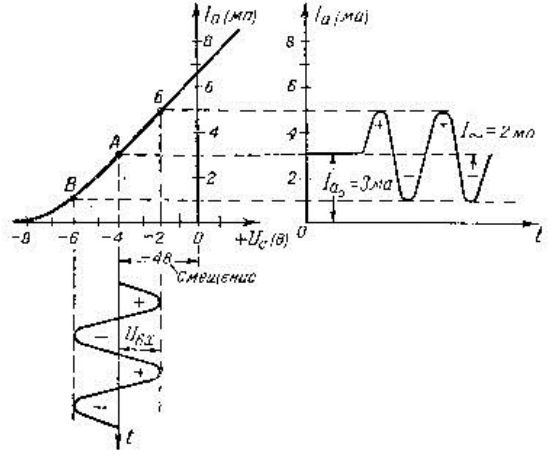

Fig. 5. The process of amplification of a vacuum threeelectrode tube of the "audion" type when applying a negative bias to the grid.

In this case, the audion detector is converted to a Class A amplifier. Class A amplifiers, as you know, work without clipping the signal in the most linear section of the currentvoltage characteristic of the amplifying elements. This ensures a minimum of non-linear distortions, both at rated power and at low powers. On average, the efficiency of a Class A amplifier is $15-30 \%$, and the power consumption does not depend on the value of the output power. The power dissipation is maximum at small output signals.

The first use of the sound amplifier was its installation in the reception company of Lowenstein, where there was an office phone in 1911.

\section{An attempt by Lowenstein to sell his invention}

Fritz Lowenstein decided to sell his invention after successful testing. On January 27, 1912, he demonstrated to the engineers the Bell Telephone System, F. B. Jewett, and O. B. Blackwell, a sound amplifier that was placed in a sealed box. This was apparently due to the fact that his invention was not yet protected by a patent. The box in which the amplifier was located contained lead gaskets to prevent X-ray imaging of the device being displayed. The performance of the amplifier was unstable and therefore Lowenstein did not disclose the features of his device. Bell Co. employees did not have even the slightest opportunity by which one could judge the suitability of the amplifier for telephone lines. As a result, Fritz Lowenstein was not able to interest Bell Co. with his invention. 
About a year passed, after which Lowenstein revealed the secret of the sealed box. It turned out to be one of de Forest's audions, which was produced and sold by Henry Wallace McCandless (1866-24.12.1957). Audion had a grid in the circuit, a galvanic cell to create a negative bias relative to the cathode of the tube.

On April 24, 1912, Fritz Lowenstein filed an application for a patent for an improved design of an audion as an amplifier for telephone lines, Fig. 6 [4].

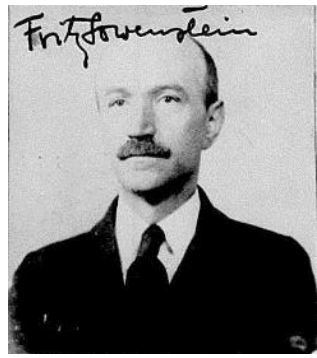

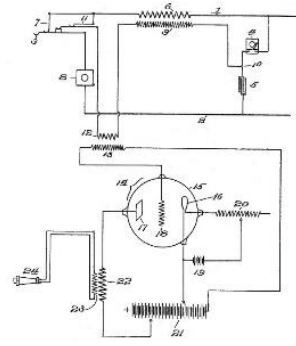

Fig. 6. Fritz Lowenstein and his patent US1231764 for an audion frequency amplifier with a negative offset to the grid (1912).

In Fritz Lowenstein's patent, the supply of a negative bias voltage to the control grid circuit was decided by connecting an appropriate galvanic battery ("C $C$ " battery).

In subsequent years, a patent with a negative bias acquired great importance and was the subject of numerous litigations.

Fritz Lowenstein received a patent for Telephone-relay only five years later after filing the application, July 3, 1917. The delay was due to the fact that the American patent US1038910 for a telephone amplifier circuit on a German lamp Lieben-Reisz (Relay for Undulatory Currents) was already issued. Lowenstein got rights only to the " $C$ " bias battery, while the amplifier circuit was not subject to him. AT\&T was forced to buy a patent from Lowenstein for $\$ 150,000$, because it used amplifiers in audio with a bias battery "C".

The invention of the audio frequency amplifier by Lowenstein did not go unnoticed. GE engineer Ernst Alexanderson, who visited Hammond, accidentally saw a tube amplifier and reported this to Irwin Langmuir. This prompted Langmuir to develop high-vacuum threeelectrode vacuum tubes to amplify and generate electrical signals in 1913.

Another person who drew attention to the potential importance of the Levenshtein audio amplifier was Beach Thompson, president of the Federal Telegraph Company in San Francisco, California, which manufactured long-range wireless telegraph systems using powerful Paulsen arc transmitters.

In 1918, Lowenstein, being in a German restaurant near the Woolworth Building, asked his friend how this happened, he cheerfully said, and then remarked in an interrogative manner: "And think for a small dry battery!" With the appropriate clarification: "But in the right place!" Fritz was so pleased with his achievement that he carried with him an exhibition of photographs of his invention, which he showed to his friends, like an Indian scalp!

\section{Research by Lee de Forest at the Federal Telegraph Company}

In early 1911, Lee de Forest, who supervised communications installations in Seattle and San Francisco, ended up on the west coast of the United States, California. Here he received the news that his New York partners in the De Forest Telephone Company were arrested for mail and stock fraud, as well as for placing unsecured shares in the amount of $\$$ $1,507,505$. A large jury was convened and the company declared bankrupt. Forest was in a deplorable state, to financial troubles were added to the family troubles, because of which he ended up in California. 
During de Forest's stay in the San Francisco Bay Area in Palo Alto, he met with employees of the Federal Telegraph, abbreviated FTC (Fig. 7), in particular, with its chief engineer Cyril Frank Elwell (08.20.1884-1963).

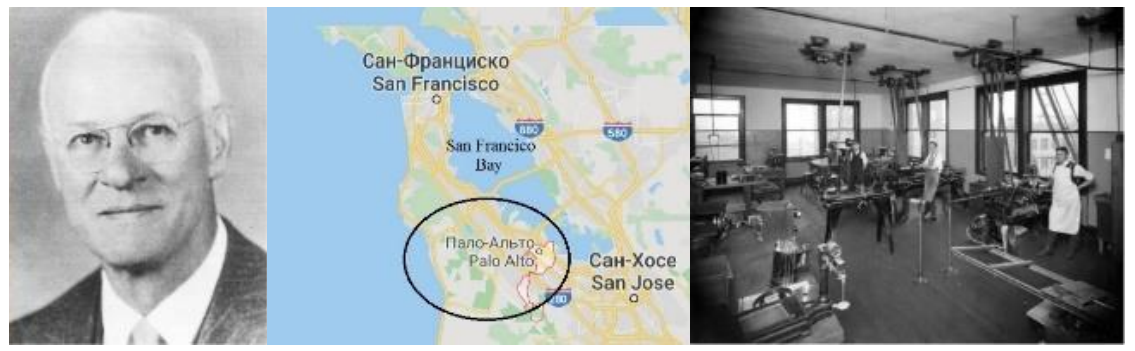

Fig. 7. Cyril Elwell (1947), a map of the San Francisco Bay Area and the workshop of the Federal Telegraph Company in Palo Alto. The dark round object in the lower left corner is a small federal arc transmitter (Photo from the collection of Perham, the history of San Jose).

Elwell thought that Forest would be useful for the FTC. He convinced Beach Thompson to hire Forest and give him a laboratory with two assistants, as well as freedom of action to develop his ideas.

In the beginning, Forest was offered work on improving the Paulsen system. However, soon the direction of research was changed. B. Thompson received a letter from John Hammond Jr. on January 25, 1912, informing about the successful testing of the iron controller (iron controller, this is one of the names of the ion controller) with the hope of its implementation in a wireless system in Sonora [5]. This was probably the starting point that prompted Thompson to turn to de Forest with a request to resume research on the development of audion as an amplifier of electrical signals in telephone lines. After all life's failures, fortune turned for Lee de Forest. On this occasion, he once said in February 1912: "Every fall brings hope; while new health, unknown physical strength, renewed youth grow in me. This is California, and I am only 38!" [6].

The offer was accepted by de Forest, because in success it promised him a certain commercial benefit. He had information that AT\&T was looking for a good sound amplifier for the proposed telephone line between New York and San Francisco. This ambitious project AT\&T promised to implement by 1915.

C. Elwell, in order to accomplish this task, on a changed research topic, organized a group led by de Forest, which included employees of the company Charles Logwood (1882-1927) and Cyril F. Elwell.

In the spring of 1912, a new employee, Herbert Van Etten, joined de Forest's group. Van Etten had previously worked for a telephone company in New York and was familiar with sound frequency electrical devices and their circuitry. In May-June 1912, Herbert van Etten, under the direction of de Forest, started experiments with transformers of audio frequency, with the aim of their application to obtain better coordination of the output of the detector radio with headphones.

Soon, de Forest received several auditions from New York. This allowed him, already in the summer of 1912, begin a series of experiments on the use of audion as an amplifier of electrical signals. In the beginning, an amplifier was built on one audion. Once, during experiments, by connecting the output of one audion with the input of another, he received a louder sound than from one single-tube amplifier. This prompted De Forest to develop cascade amplifiers. The approach in the design of powerful audio amplifiers in the form of cascades, proposed by de Forest, later began to be used in radio engineering.

To match the amplifier cascades with each other, de Forest used low-frequency transformers, also known from electrical engineering. In addition to the two-stage amplifiers, even more powerful three-stage amplifiers on the audio have been developed. 
In de Forest's amplifiers, the setting of the bias value on the audio grids was different from the Fritz Lowenstein technology. The offset was set by selecting the anode voltage to minimize sound distortion at the output of the amplifier. This was done with step-controlled variable resistors that were installed in each stage of the amplifier. For these purposes, later they began to use a variable resistor in the filament circuit.

Soon, de Forest received several audios from New York. This allowed him in the summer of 1912, begin a series of experiments on the use of audion as an amplifier of electrical signals. In the beginning, a single-audio amplifier was built. Once, during experiments, connecting the output of one audio with the input of another, it received a louder sound than from one single-tube amplifier. This prompted de Forest to develop cascade amplifiers. The approach in the design of high-power audio amplifiers in the form of cascades, proposed by de Forest, was later used in radio engineering.

To coordinate the amplifier stages among themselves, de Forest used low-frequency transformers, known from electrical engineering. In addition to the two-stage amplifiers, even more powerful three-stage amplifiers on audios were developed.

In de Forest's amplifiers, setting the offset value on the audio grids differed from Fritz Lowenstein's technology. The bias was set by selecting the anode voltage to minimize sound distortion at the amplifier output. This was done by variable resistors with step regulation, which were installed in each stage of the amplifier. For these purposes, later began to use a variable resistor in the filament circuit.

The amount of playback volume of audio signals, design of amplifiers, was determined by de Forest in subjective manner. To do this, he installed an acoustic radiator on the windowsill of an open laboratory window, and he moved away from it to the maximum limit of hearing. In the first designs of two-stage amplifiers, the anode voltage was $50-60 \mathrm{~V}$ and the gain was not much greater than a single-stage amplifier. The reason for this appeared to be due to the low vacuum of the audios. Then de Forest gathered up all the audios he had and went to San Francisco to see a manufacturer of X-ray tubes. He was able to obtain a much higher vacuum in the audions than it was earlier, and thus raise the anode voltage in the amplifier to $200 \mathrm{~V}$. As a result of these experiments, a twostage amplifier with acceptable characteristics was developed, which later became its invaluable device, Fig. 8.

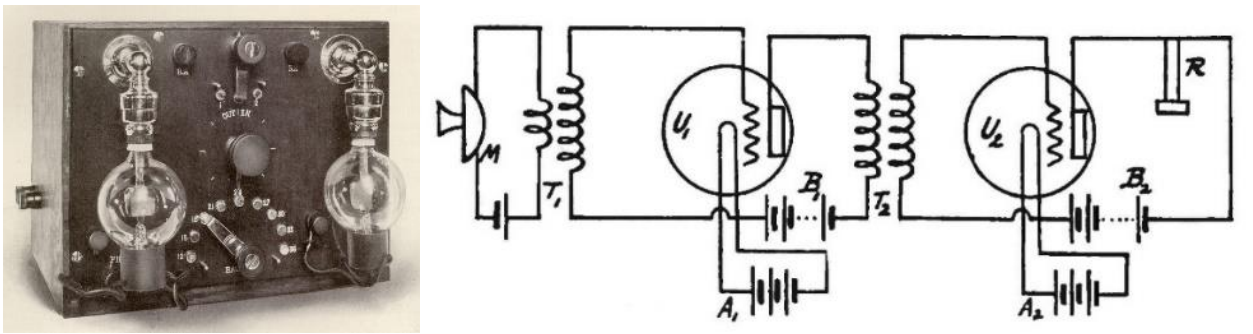

Fig. 8. Schematic diagram of a two-stage audion frequency amplifier at de Forest's audions and its general appearance in the form of a finished design. 1914.

At the most intense moment of development in Palo Alto in 1912, federal agents arrived to arrest de Forest in connection with a stock fraud scheme. B. Thompson helped to get out of the difficult situation. He made a deposit of $\$ 10,000$, which allowed de Forest to continue his work.

In September 1912, the FTC sent the first autonomous three-stage amplifier to Washington to demonstrate it to the U.S. Navy, Fig. 9. This amplifier was assembled in a wooden case, inside of which there were: three audions, switches, resistors, transformers, a flat galvanic battery and terminals for connecting an external battery to power the filaments of the tubes. Dr. Louis Austin, then head of the U.S. Naval Radio Telegraph Laboratory, 
took the amplifier to the bureau of standards and measured its gain. Using the imperfect methods available at the time, it was determined that a three-stage amplifier amplifies the signal 120 times.
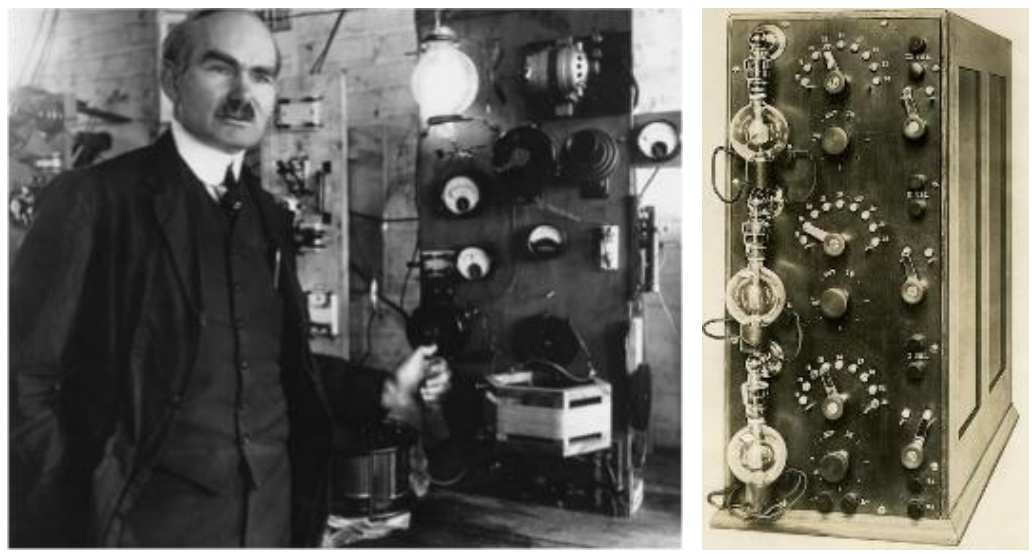

Fig. 9. Lee de Forest, Palo Alto (1915) and a general view of a three-stage audio amplifier at audions (1912).

In October 1912, Lee de Forest brought one of his audio amplifiers to New York to show it to his friend J. Stone. J. Stone worked at Bell Telephone Co. from 1890 to 1899 in Boston (Massachusetts), in particular, a research and development laboratory experimental department. After leaving the company, Stone worked in Boston as an independent consultant engineer, but along with this he maintained a good relationship with AT\&T and often rendered her services as a "consultant and expert in patent matters." De Forest's audio amplifier impressed J. Stone. He saw great potential for telephone communications in the device, and promised to organize his presentation for engineers and AT\&T managers.

This is what Lee de Forest was striving for. If successful, the way was opened for the practical implementation of the audion in a grandiose commercial and technical project, which promised considerable financial benefits for the entire chain of Lee de Forest - AT \& $\mathrm{T}$. On the other hand, the time of inventors alone, the prominent representative of which was Lee de Forest, was coming to an end, they were to be replaced by scientific teams (schools) capable of solving large-scale scientific and technical projects. But the most important thing was that society, thanks to scientific and technological progress, was rising to a new stage of development. The era of informatization was gaining momentum, distances were shortening, and time was accelerating.

Lee de Forest left the FTC in 1913 to establish his own Radio Telegraph and Telephone Company, which did not last long. The company was located in the central west Bronx area of New York.

\section{Business of De Forest Radio Telephone \& Telegraph Company}

In 1916, the Russian Defense Ministry made purchases of radio equipment in different countries of the world [7]. In the USA, not only the audions themselves were purchased from De Forest Radio Telephone \& Telegraph Co., but also the equipment based on them.

In the Russian maritime department, an "Audion amplifier" (double audion) and an "Audion detector" lamp were used. The "Audion amplifier" lamp had two arcuate curved filaments designed by Hudson. The Audion detector lamp used as a detector differed from the one described above in that only one thread was heated in it and the other spare thread was connected if necessary. In "Audion detector" the anode and the grid were located only 
on one side of the filament and their device was such as that of "Audion amplifier". Fig. 10 shows the anode-grid characteristics of the "Audion detector" at an anode voltage of $30 \mathrm{~V}$ taken in the Radio Telegraph office of the Officer Electrotechnical School in St. Petersburg.
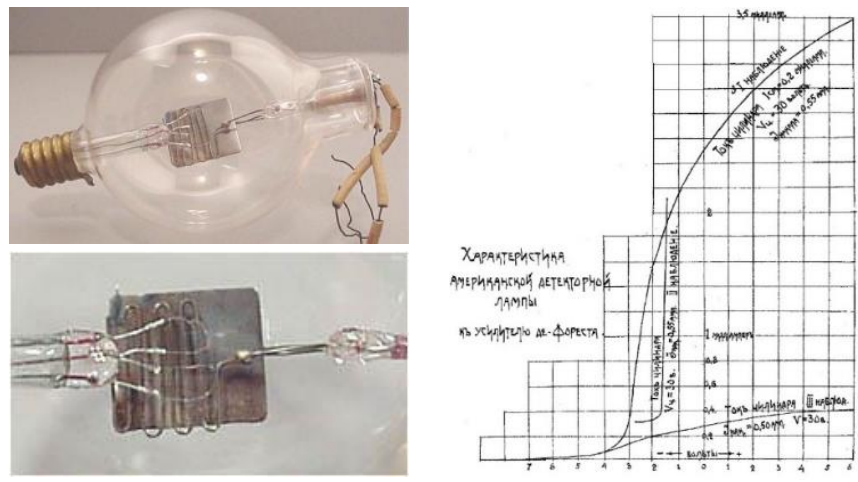

Fig. 10. General view of the "Audion detector" by Lee de Forest and its anode-grid characteristics (1917).

Among the radio equipment purchased in the United States were, in particular, detector radios with a crystalline detector and a three-stage audio frequency amplifier with double audions, Fig. 11. The radio receivers of de Forest's design, before being delivered to the troops, were tested in the Radio Telegraph Office of the Officer Electrotechnical School by Lieutenant Alexander Tikhonovich Uglov, Acting Head of the Electrical Cabinet, with the participation of Lieutenant Magnushesky, Commander of the 1st Radio Telegraph Company of the spare electrical battalion.

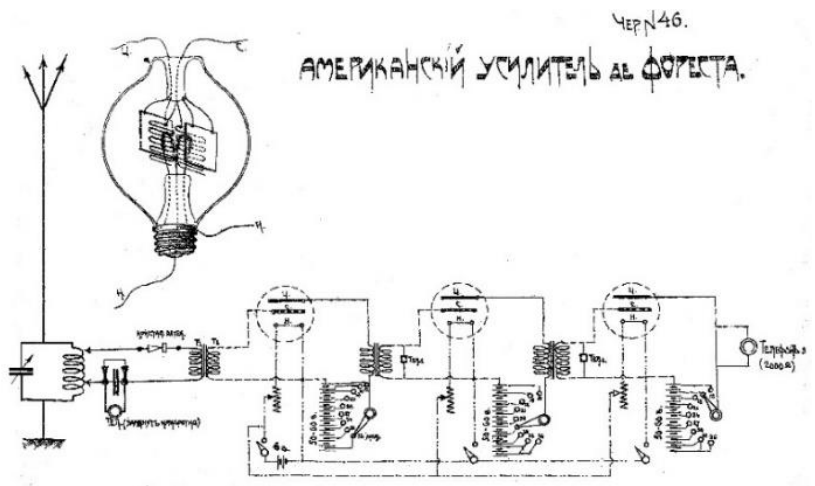

Fig. 11. Schematic diagram of a detector radio with a three-stage sound frequency amplifier designed by Lee de Forest, which was delivered to Russia. 1916.

The audio amplifier of Lee de Forest had three amplification stages in double audions. The connection between the cascades was of transformer type. The output signal from the detector of the radio was fed to the primary winding of the transformer, and then from its secondary winding to the grid of the first lamp of the amplifier. For filament, a $6 \mathrm{~V}$ battery was used, common to all three lamps. The incandescent current of each lamp was regulated by a rheostat approximately according to the strength of the glow of the filament.

The anode voltage for each lamp was supplied from a separate battery consisting of 36 dry cells with a voltage of about $60 \mathrm{~V}$. The anode battery had 8 pins that were used to change the anode voltage. By stepwise changing the anode voltage and smoothly changing the filament of the filament with a rheostat, it was possible to find a point on the rectilinear portion of the lamp characteristic at which the potential on the grid became zero. The normal operation of the lamp corresponded to an anode voltage of 18-24 V. The service life of the new anode battery was $8-12$ months. When adjusting, it was necessary to ensure 
that the blue light did not appear in the lamps, as this could lead to destruction of the thread. In these cases, it was recommended to reduce the incandescence or anode voltage, or both. Fine adjustment for sound power was made by one glow rheostat when the anode voltage was already set.

To listen to radio messages, telephone headphones with a resistance of at least 2000 Ohms were used, which were connected directly to the anode circuit of the output lamp. The radio provided for the operation of the receiver without a sound amplifier. For this, the detector circuit had jacks for connecting headphones. These sockets during operation of the tube amplifier were shorted by a jumper.

\section{Conclusions}

Audion of de Forest was first used as a detector. Innovative technologies developed by Fritz Lowenstein for the construction of amplifiers of electrical signals, made it possible to assemble the first audio frequency amplifiers in audion. Subsequently, they became the basis of high-frequency generators.

Thanks to the audio amplifier working in the mode of amplification of electrical signals, it was possible to connect a loudspeaker to the radio. This made it possible to listen to the broadcasts of an entire audience, while the detector receiver made it possible to listen to headphones and only with complete silence. For a long time, to obtain the required bias on the grid of the vacuum triode, galvanic cells were used until they were replaced in some cascades of radio receivers by the grid-leak (1920).

It should be noted that the development of a sound amplifier in FTC provided little to the company in the short term, it became significant in the 1920's, when the growing dominance of vacuum tube technology forced the FTC to switch from the Paulsen arc to vacuum electron tube systems.

\section{References}

1. Bronk O. von. Patent für DRP271059 vom 3. September 1911 über eine "Empfangseinrichtung für drahtlose Telegraphie" (2011)

2. Stone J.S. \& Cabot S. Space Telegraphy. Patent US884110A. Application Field Jan. 4.1907. Patented Apr. 7, 1908 (1908)

3. Discussion of "A History of Some Foundations of Modern Radio-Electronic Technology". Proceedings of the IRE. No. 7. P. 1254 (1959)

4. Lowenstein Fritz. Telephone relay. Patent US12478717A. Application Field Apr.24.1912. Renewed Apr. 26, 1917. Patented July 3, 1917 (1917)

5. Discussion of "A History of Some Foundations of Modern Radio-Electronic Technology". Proceedings of the IRE. No. 7. P. 1255 (1959)

6. De Forest's diary, February 12, 1912; entry in his notebook, April 22, 1912, Papers of Lee de Forest, Library of Congress, Washington DC (1912)

7. Uglov A.E. Atlas of drawings for the course amplifying tubes of wireless telegraphy and telephony. Petrograd. 38 P. (1917) 